\title{
Association of traffic-related hazardous air pollutants and cervical dysplasia in an urban multiethnic population: a cross-sectional study
}

Michael E Scheurer ${ }^{1 *}$, Heather E Danysh ${ }^{1}$, Michele Follen ${ }^{2}$ and Philip J Lupo ${ }^{1}$

\begin{abstract}
Background: Human papillomavirus (HPV) infection is a necessary cause in the development of cervical cancer; however, not all women infected with HPV develop cervical cancer indicating that other risk factors are involved. Our objective was to determine the association between exposure to ambient levels of common traffic-related air toxics and cervical dysplasia, a precursor lesion for cervical cancer.

Methods: The study sample consisted of women enrolled in a Phase II clinical trial to evaluate diagnostic techniques for cervical disease in Houston, Texas. The current assessment is a secondary data analysis in which cases were defined as women diagnosed with cervical dysplasia, while those without cervical dysplasia served as controls. Residential census tract-level estimates of ambient benzene, diesel particulate matter (DPM), and polycyclic aromatic hydrocarbons (PAHs) were used to assess exposure. Census tract-level pollutant estimates were obtained from the United States Environmental Protection Agency. Multivariable logistic regression was used to estimate prevalence odds ratios (aOR) and 95\% confidence intervals (Cl) adjusted for age, race/ethnicity, education, smoking status, and HPV status.

Results: Women in the highest residential exposure categories for benzene and DPM had an increased prevalence of cervical dysplasia compared to the lowest exposure category (Benzene: aOR [95\% Cl] for high exposure $=1.97$ [1.07-3.62], very high exposure $=2.30[1.19-4.46]$. DPM: aOR [95\% Cl] for high exposure $=2.83[1.55-5.16]$, very high exposure $=2.10[1.07-4.11])$. Similarly, women with high residential exposure to PAHs had an increased prevalence of cervical dysplasia (aOR $[95 \% \mathrm{Cl}]=2.46[1.35-4.48])$. The highest PAH exposure category was also positively associated with cervical dysplasia prevalence but was not statistically significant. Assessment of the combined effect of HAP exposure indicates that exposure to high levels of more than one HAP is positively associated with cervical dysplasia prevalence ( $p$ for trend $=0.004$ ).
\end{abstract}

Conclusions: Traffic-related HAPs, such as benzene, DPM, and PAHs, are not as well-regulated and monitored as criteria air pollutants (e.g., ozone), underscoring the need for studies evaluating the role of these toxicants on disease risk. Our results suggest that exposure to traffic-related air toxics may increase cervical dysplasia prevalence.

Keywords: Benzene, Cervical dysplasia, Diesel particulate matter, Hazardous air pollutants, Polycyclic aromatic hydrocarbons

\footnotetext{
* Correspondence: scheurer@bcm.edu

${ }^{1}$ Department of Pediatrics, Section of Hematology-Oncology and Dan L.

Duncan Cancer Center, Baylor College of Medicine, Houston, Texas

Full list of author information is available at the end of the article
} 


\section{Background}

Cervical cancer is the third most common cancer and the fourth leading cause of cancer-related mortality among women worldwide [1]. The majority $(>85 \%)$ of cervical cancer cases and deaths occur in the developing world [1], largely due to limited screening programs which allow for the detection of cervical dysplasia (precancerous lesions) and early stage cervical cancer [2-4]. Infection with human papillomavirus (HPV) has been established as a necessary cause in the development of cervical cancer; however, most women infected with HPV do not develop cervical cancer [5,6]. Lifestyle factors, such as sexual behavior and smoking cigarettes $[7,8]$, use of oral contraceptives $[9,10]$, high parity $[10,11]$, as well as co-infections, such as human immunodeficiency virus infection [12], are associated with the development of cervical cancer. Taken together these findings suggest that genetic and/or environmental factors may play a role in the development of this malignancy [13].

Air pollution is largely composed of automobile emissions, a complex mixture of compounds many of which are known to adversely affect human health. Benzene, polycyclic aromatic hydrocarbons (PAHs), and diesel particulate matter (DPM) are components of automobile emissions and have been designated by the United States Environmental Protection Agency (U.S. EPA) as hazardous air pollutants (HAPs) [14]. HAPs are toxic substances known or suspected to be carcinogenic. In fact, the International Agency for Research on Cancer has classified benzene and DPM as carcinogenic compounds, and many PAHs as possible, probable, or known carcinogens [15-17]. Some studies have suggested that exposure to traffic-related air pollutants, such as benzene, PAHs, and DPM, is associated with an increased risk for several types of cancer, including lung cancer $[18,19]$, brain cancer [20,21], and leukemia [22-24]. The carcinogenic impact of exposure to traffic-related air pollution is an ever-increasing public health concern as urbanization continues to rise, and a greater proportion of the population is exposed to higher levels of HAPs.

Exposure to traffic-related HAPs may play a role in the development of cervical cancer. Occupational exposure to diesel engine exhaust has previously been shown to be associated with an increased risk of cervical cancer among women [25]. In addition, a recent study found an increased risk of cervical cancer in Danish women with higher residential concentration levels of nitrogen oxides $\left(\mathrm{NO}_{\mathrm{x}}\right)$, a component of automobile engine emissions [21]. The objective of the current study is to evaluate the association between levels of trafficrelated HAPs and cervical dysplasia, a precursor lesion for cervical cancer, in a multi-ethnic sample of women receiving cervical cancer screening and diagnostic services in Houston, Texas.

\section{Methods}

\section{Study population}

The study population consisted of women attending the colposcopy clinics at The University of Texas MD Anderson Cancer Center and Lyndon B. Johnson General Hospital in Houston, Texas, between 2000 and 2004, and enrolled in a multi-center Phase II clinical trial (registered at www.ClinicalTrials.gov as NCT00511615) to evaluate fluorescence and reflectance spectroscopy for diagnosing cervical disease. The detailed data collection methods for this trial have been previously described [26]. Briefly, women had to be 18 years of age or older, have no history of hysterectomy, and not be pregnant to be eligible for enrollment in the parent trial. Of those who were eligible and enrolled in the parent trial, only women who had available information on HPV infection status and residence (i.e., address) at the time of diagnosis were eligible for our study, a secondary data analysis using data collected during the parent trial. After applying all eligibility criteria, 736 women were included in the current assessment. Cases $(n=173)$ included women who were diagnosed with cervical intraepithelial neoplasia (CIN) I, CIN II, or CIN III. Women who had a normal Papanicolaou test result (i.e., not diagnosed with cervical dysplasia or cervical cancer) served as control subjects $(n=563)$. Details on the laboratory methods used to test for HPV status as well as those used to confirm cervical dysplasia disease status have been previously described [26]. Epidemiologic data were obtained from a risk factor interview conducted with each patient at the time of enrollment on the parent trial. Women received the standard treatment according to their colposcopy results. The Institutional Review Boards at the University of Texas MD Anderson Cancer Center and Harris Health System approved the protocol for the parent trial. Informed consent was obtained from all subjects.

\section{Ambient air pollutant concentration levels}

Annual concentration estimates of benzene, DPM, and PAHs were obtained for each census tract from the U.S. EPA's 1999 Assessment System for Population Exposure Nationwide (ASPEN). ASPEN is a computer simulation model used in the National-Scale Air Toxics Assessment conducted by the U.S. EPA [27]. The ASPEN model was derived from the U.S. EPA's Industrial Source Complex Long Term model designed to model air pollutant dispersion. To generate annual pollutant concentration estimates, ASPEN uses information on meteorological conditions, the location and height of pollutant release, rate of release, and pollutant deposition, reactive decay, and transformation properties. Other epidemiological studies have used pollutant concentration estimates from ASPEN to evaluate the effect of HAPs on disease risk [23,28,29].

Residential pollutant levels were determined based on the ASPEN estimates for the census tract of the subject's 
residence at the time of the clinic visit. Addresses were geocoded and mapped to determine residential census tracts using ArcGIS software (Esri, Redlands, California). Benzene, DPM, and PAH levels from ASPEN were categorized using the distribution of the residential HAP levels among the controls: low or reference exposure $(<25$ th percentile), medium exposure (25th-74th percentiles), high exposure (75th-89th percentiles), and very high exposure ( $\geq 90$ th percentile). In addition, a HAP composite score was created to assess the combined effect of exposures to multiple HAPs on cervical dysplasia. To create the HAP composite score, each exposure category of each HAP was assigned a score: $0=$ low, $1=$ medium, $2=$ high, and $3=$ very high. The scores from the three HAPs were then summed for each subject based on their residential census tract in order to generate the overall HAP composite score, which could range from $0-9$.

\section{Statistical analysis}

Descriptive statistics were generated to characterize the demographic variables among the case and control groups, which included computing means and standard deviations (SD) for continuous variables and frequency distributions for categorical variables. Potential differences between the case and control groups in the distribution of each of the demographic variables were tested for statistical significance using $t$ tests for continuous variables and $\chi^{2}$ tests for categorical variables. Correlations between levels of benzene, DPM, and PAHs were determined using Spearman's rank correlation. We used multivariable logistic regression to assess the associations between HAP levels and cervical dysplasia. Adjusted prevalence odds ratios (aOR) and 95\% confidence intervals (CI) were estimated for each association. Covariates were selected a priori and included age, race/ethnicity, years of completed education, HPV infection status $[30,31]$, and smoking status. All multivariable regression models were adjusted for these covariates. Univariable logistic regression analyses were conducted to evaluate the associate between cervical dysplasia and demographic variables, including age, race/ethnicity, smoking status, and completed years of education, variables which also serve as covariates in the adjusted analyses. These results were included in Additional file 1: Table S1.

\section{Results}

There were no statistically significant differences between the case and control groups in regard to racial makeup, completed years of education, smoking status, HPV infection status, and the screening institution (Table 1). Approximately half of the sample was non-Hispanic white (52.5\%), with a quarter being Hispanic (24.2\%) and fewer being non-Hispanic black (16.0\%). This racial/ethnic distribution approximates the distribution of the population
Table 1 Characteristics of cervical dysplasia cases and controls from colposcopy clinics in Houston, Texas, 2000-2004

\begin{tabular}{|c|c|c|c|}
\hline Characteristic & $\begin{array}{c}\text { Cases } \\
(n=173)\end{array}$ & $\begin{array}{l}\text { Controls } \\
(n=563)\end{array}$ & P-value \\
\hline Age in years, mean $\pm S D$ & $37.0 \pm 11.0$ & $43.5 \pm 11.8$ & $<0.001$ \\
\hline \multicolumn{4}{|l|}{ Race/ethnicity, n (\%) } \\
\hline Non-Hispanic White & $90(52.0)$ & $296(52.6)$ & 0.180 \\
\hline Non-Hispanic Black & $36(20.8)$ & $85(15.1)$ & \\
\hline Hispanic & $39(22.5)$ & $137(24.3)$ & \\
\hline Other & $8(4.6)$ & $45(8.0)$ & \\
\hline Education in years, mean $\pm S D$ & $13.1 \pm 1.98$ & $13.4 \pm 3.57$ & 0.376 \\
\hline \multicolumn{4}{|l|}{ Marital status, $n(\%)$} \\
\hline Never & $45(26.0)$ & $102(18.2)$ & 0.038 \\
\hline Married/partnered & $85(49.1)$ & $331(58.9)$ & \\
\hline Divorced/widowed/separated & $43(24.9)$ & $129(23.0)$ & \\
\hline \multicolumn{4}{|l|}{ Smoking status, $n(\%)$} \\
\hline Never & $108(62.4)$ & $389(69.1)$ & 0.101 \\
\hline Ever & $65(37.6)$ & $174(30.9)$ & \\
\hline \multicolumn{4}{|l|}{ HPV status, $n(\%)$} \\
\hline Positive & $129(74.6)$ & $408(72.5)$ & 0.587 \\
\hline Negative & $44(25.4)$ & $155(27.5)$ & \\
\hline \multicolumn{4}{|l|}{ Histology, n (\%) } \\
\hline CIN I (mild dysplasia) & $141(81.5)$ & & \\
\hline CIN II (moderate dysplasia) & $19(11.0)$ & & \\
\hline CIN III (severe dysplasia) & $13(7.5)$ & & \\
\hline \multicolumn{4}{|l|}{ Clinic, $n(\%)$} \\
\hline MD Anderson Cancer Center & $141(81.0)$ & $481(85.4)$ & 0.153 \\
\hline Lyndon B. Johnson General Hospital & $33(19.0)$ & $82(18.6)$ & \\
\hline
\end{tabular}

Abbreviations: SD, standard deviation; HPV, human papillomavirus; $\mathrm{CIN}$, cervical intraepithelial neoplasia.

in the Houston area. The mean (SD) completed years of education was 13.3 (3.3) years. Approximately one-third of the sample (32.5\%) had a history of smoking. Most of the subjects (both cases and controls) were positive for HPV infection (73.0\%); $27.0 \%$ were HPV negative. The majority of the sample $(84.4 \%)$ was screened at the colposcopy clinic at the University of Texas MD Anderson Cancer Center, while the remainder (15.6\%) was screened at the Lyndon B. Johnson General Hospital. Cases were younger $(p<0.001)$ and more likely to have never been married $(p=0.04)$ compared to controls. Cases primarily had CIN I (81.5\%) while the remainder of the cases had moderate to severe dysplasia (18.5\%). All controls were confirmed to not have cervical dysplasia.

The distributions of selected census tract-level HAP concentration levels among the control group are presented in Table 2. The mean benzene exposure level among the controls was $1.917 \mu \mathrm{g} / \mathrm{m}^{3}$, with the lowest 
Table 2 Distributions of hazardous air pollutants

\begin{tabular}{lccccc}
\hline Pollutant $\left(\boldsymbol{\mu} \mathbf{g} / \mathbf{m}^{\mathbf{3}}\right)^{*}$ & Mean & $\mathbf{2 5}^{\text {th }}$ percentile & $\mathbf{5 0}^{\text {th }}$ percentile & $\mathbf{7 5}^{\text {th }}$ percentile & $\mathbf{9 0}^{\text {th }}$ percentile \\
\hline Benzene & 1.917 & 1.415 & 1.760 & 2.261 & 2.977 \\
DPM & 2.015 & 1.413 & 1.724 & 2.175 & 2.794 \\
PAHs & 0.011 & 0.007 & 0.009 & 0.013 & 0.018 \\
\hline
\end{tabular}

Abbreviations: DPM, diesel particulate matter; $\mathrm{PAHs}$, polycyclic aromatic hydrocarbons.

${ }^{*}$ All concentrations are presented as $\mu \mathrm{g} / \mathrm{m}^{3}$.

$\left(<25^{\text {th }}\right.$ percentile) and highest $\left(\geq 90^{\text {th }}\right.$ percentile) exposure categories representing those living in census tracts with an estimated average benzene level $<1.415 \mu \mathrm{g} / \mathrm{m}^{3}$ and $\geq 2.977 \mu \mathrm{g} / \mathrm{m}^{3}$, respectively. Similarly, the mean level of DPM and PAHs among the controls was $2.015 \mu \mathrm{g} / \mathrm{m}^{3}$ and $0.011 \mu \mathrm{g} / \mathrm{m}^{3}$, respectively. The lowest and highest exposure categories included those living in census tracts with an estimated average DPM level $<1.413 \mu \mathrm{g} / \mathrm{m}^{3}$ and $\geq 2.794 \mu \mathrm{g} / \mathrm{m}^{3}$, respectively. For PAHs, the lowest exposure category was $<0.007 \mu \mathrm{g} / \mathrm{m}^{3}$ and the highest exposure category was $\geq 0.018 \mu \mathrm{g} / \mathrm{m}^{3}$.

Scatterplots of benzene and each of the other HAPs (i.e., DPM and PAHs) are presented in Figure 1 to assess correlations between the pollutant levels. Overall, benzene levels are highly correlated with levels of DPM $(\rho=0.91, p<0.0001)$ and PAHs $(\rho=0.80, p<0.0001)$. However, these correlations were not as strong when restricted to those in the "very high" exposure category. Specifically, when restricting the correlation analysis to those in the very high benzene exposure category $(n=83)$ the correlations with DPM $(\rho=0.66, p<0.0001)$ and PAHs ( $\rho=0.65, p<0.0001)$ are attenuated.

The aORs and 95\% CIs of the associations between residential exposure to benzene, DPM and PAH's and the prevalence of cervical dysplasia are presented in Table 3. Residential exposure to benzene was associated with cervical dysplasia (aOR medium exposure $=1.39$, 95\% CI: 0.83-2.32; aOR high exposure $=1.97,95 \%$ CI: 1.07-3.62; and aOR very high exposure $=2.30,95 \% \mathrm{CI}$ : 1.19-4.46) after adjusting for age, race/ethnicity, years of education, HPV infection status, and smoking. We also observed a trend with increasing exposure ( $p$ for trend $=0.005$ ). Residential exposure to DPM is positively associated with cervical dysplasia when comparing high and very high exposure to low exposure (aOR for high exposure $=2.83$, 95\% CI: $1.55-5.16$; aOR for very high exposure $=2.10,95 \%$ CI: 1.07-4.11). Compared to low exposure, women living in census tracts with high levels of PAHs had an increased prevalence of cervical dysplasia $(\mathrm{aOR}=2.46,95 \% \mathrm{CI}: 1.35-4.48)$. The effect estimates for medium or very high exposure to PAHs suggest an increased prevalence of cervical dysplasia; however, these associations are not statistically significant. When assessing the combined effect of HAP exposure as defined using the HAP composite score, there is a positive association with cervical dysplasia prevalence when comparing women with a higher (score of $3+$ ) HAP composite score to those with a low composite score (score $<3$ ) (aOR for medium score $=1.78,95 \% \mathrm{CI}$ : 1.11-2.84; aOR for high score $=2.30,95 \%$ CI: 1.28-4.13). All regression analyses were repeated on a restricted sample that excluded cases with mild dysplasia, which yielded similar results (data not shown), and therefore we retained the grouping of

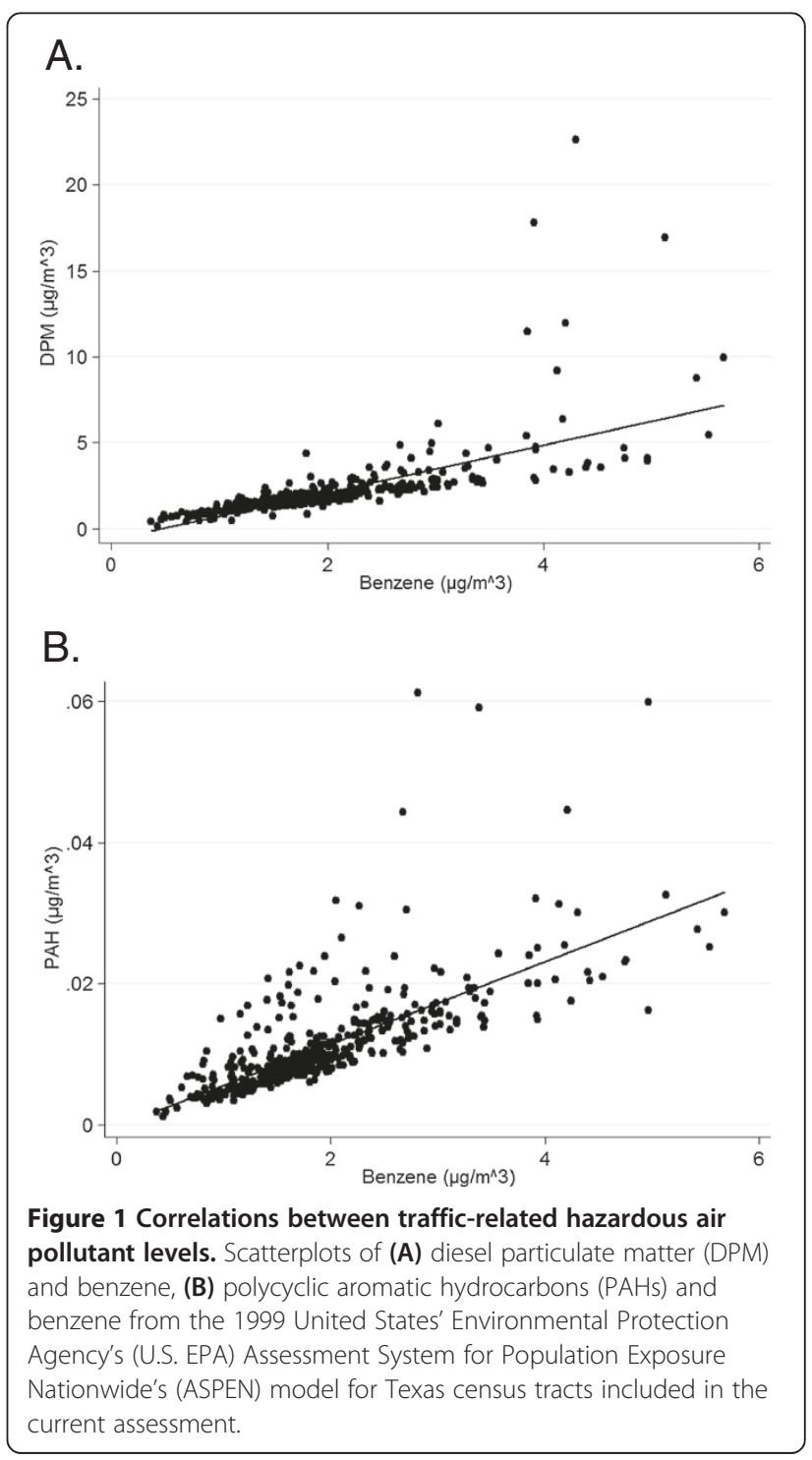


Table 3 Associations between selected traffic-related hazardous air pollutants and cervical dysplasia

Pollutant
Lowzene $\left(<25^{\text {th }}\right.$ percentile)
Medium ( $25^{\text {th }}-74^{\text {th }}$ percentile)
High ( $75^{\text {th }}-89^{\text {th }}$ percentile)
Very high ( $\geq 90^{\text {th }}$ percentile)
DPM
Low ( $<25^{\text {th }}$ percentile)
Medium $\left(25^{\text {th }}-74^{\text {th }}\right.$ percentile)
High $\left(75^{\text {th }}-89^{\text {th }}\right.$ percentile)
Very high ( $\geq 90^{\text {th }}$ percentile)
PAHs
Low $\left(<25^{\text {th }}\right.$ percentile)
Medium ( $25^{\text {th }}-74^{\text {th }}$ percentile)
High $\left(75^{\text {th }}-89^{\text {th }}\right.$ percentile)
Very high $\left(\geq 90^{\text {th }}\right.$ percentile)

HAP composite

Low (score 0-2)

Medium (score 3-6)

High (score 7-9)

1.00

$1.39[0.83,2.32]$

$1.97[1.07,3.62]$

$2.30[1.19,4.46]$

1.00

$1.41[0.84,2.37]$

$2.83[1.55,5.16]$

$2.10[1.07,4.11]$

1.00

$1.30[0.77,2.20]$

$2.46[1.35,4.48]$

$1.88[0.94,3.73]$

1.00

$1.78[1.11,2.84]$

$2.30[1.28,4.13]$
Prevalence aOR* $[95 \% \mathrm{Cl}]$

$P$ for trend $=0.005$

$P$ for trend $=0.002$

$P$ for trend $=0.006$

$P$ for trend $=0.004$

Abbreviations: aOR, adjusted odds ratio; $\mathrm{Cl}$, confidence interval; DPM, diesel particulate matter; PAHs, polycyclic aromatic hydrocarbons; HAP, hazardous air pollutant.

*Odds ratios adjusted for age, race/ethnicity, education, smoking status, and status of human papilloma virus (HPV) infection.

mild and progressive cervical disease in our final models $[30,32]$. Moreover, regression analyses were repeated stratifying the sample on HPV infection status, and the overall results were similar regardless of HPV status (data not shown).

\section{Discussion}

In one of the first studies of its kind, our results indicate traffic-related HAPs are associated with cervical dysplasia. Specifically, women living in census tracts with high levels of benzene, DPM, or PAHs were approximately two to three times more likely to be diagnosed with cervical dysplasia compared to women living in census tracts with relatively low pollutant levels. We also observed a statistically significant dose-response relationship between each pollutant and cervical dysplasia prevalence ( $p$ for trend $\leq 0.006$ for benzene, PAHs, and DPM). These findings are notable as cervical dysplasia in conjunction with chronic HPV infection is a precursor of cervical cancer. In fact, $18.5 \%$ of our cases had medium to severe dysplasia (CIN II or higher), lesions associated with an increased risk of progression to cervical cancer, and the majority of the women in our sample were positive for HPV infection.

While previous studies have not evaluated the role of air pollution on the risk of cervical dysplasia, our findings are in keeping with previous reports of an increased risk of cervical cancer after exposure to traffic-related pollutants and HAPs $[21,25]$. In a recent assessment by Raaschou-Nielsen et al. using data from the Danish Diet Cancer and Health cohort, residential exposure to $\mathrm{NO}_{\mathrm{x}}$ was associated with an increased risk of cervical cancer (incidence rate ratio $=2.45,95 \%$ CI: 1.01-5.93) [21]. Another study conducted in Sweden indicated that occupational exposure to diesel engine emissions was associated with an increased incidence of cervical cancer (standardized incidence ratio $=1.48,95 \%$ CI: 1.17-1.84) [25]. Our study builds upon these assessments by including a multi-ethnic population and evaluating cervical dysplasia rather than cervical cancer. In addition, there is considerable variation in HAP concentration levels between the HAP exposure categories defined in our analysis, which also includes HAP levels positively associated with adverse health risks [33].

Our findings are consistent with the role of cigarette smoking on cervical cancer risk. A large body of epidemiological evidence supports the association between cigarette smoking and cervical cancer risk [34-36]. In fact, when assessing smoking as a predictor of cervical cancer among women who have a confirmed HPVpositive status, those who were current or ever smokers had a two times greater risk of developing cervical cancer compared to never smokers $(\mathrm{OR}=2.17,95 \% \mathrm{CI}$ : 1.46-3.22) [8]. Even passive exposure to cigarette smoke (i.e., second-hand smoke) may increase the risk of cervical cancer [37]. These previously reported associations are of note, as cigarette smoke contains carcinogenic compounds similar to those found in automobile emissions (e.g., benzene and PAHs), and, consequently, the effect of exposure to traffic-related air pollutants may be analogous to the effect of smoking on cervical cancer risk.

While the mechanism underlying the association between these pollutants and cervical dysplasia is unclear, there are certain biological pathways that may lead to dysplasia after exposure to HAPs. For instance, these HAPs may have genotoxic effects on the cervix. This is supported by evidence of high levels of PAHs in cervical mucus and cervical tissue among smokers [38]. PAHDNA adducts have also been found in the cervical tissue of smokers [39]. These adducts have genotoxic properties, which may lead to cancer. It is unknown if benzene or DPM has been identified in cervical tissue, however, 
these compounds are also known to have genotoxic effects $[15,16]$. Another potential mechanism may be related to oxidative stress, as these pollutants have been shown to form reactive oxygen species, leading to DNA damage [40]. These pollutants may also play a role in an altered immune environment leading to a state of chronic inflammation [41,42]. Ultimately, it is suspected that these pollutants may lead to a state of DNA damage and/or inflammation, which may facilitate viral integration, resulting in enhanced cervical carcinogenesis. For instance, some evidence suggests that PAHs may actually play a role in the proliferation and persistence of HPV [43].

There are several limitations to consider when interpreting the results presented in this report. First, the cross-sectional study design and the inclusion of prevalent cases of cervical dysplasia make it difficult to assess temporality in terms of the timing of exposure and the development of disease. However, it is not uncommon to evaluate prevalent cases when assessing an asymptomatic condition that requires an invasive screening technique for detection [26]. Second, ASPEN yields areabased pollutant concentration estimates and therefore exposure misclassification is a possibility. Although we used an area-based exposure measure there are few sources of population-based exposure assessments of HAPs. Additionally, ASPEN pollutant concentration estimates have been used extensively in other assessments of HAPs and adverse health outcomes [23,28,29]. Lastly, it is not clear if the women in this assessment later developed more progressive cervical disease or cervical cancer; however, cervical dysplasia is an important precursor to cervical cancer and therefore it is important to understand risk factors for cervical dysplasia.

To our knowledge, this study is the first to evaluate the association of air pollution exposure and predictors of cervical dysplasia in a racially diverse sample of women. A growing body of evidence shows that there are disparities in air pollution exposure among racial minorities and those with a low socioeconomic status [44-46]. Racial minorities are more likely to live in urban areas with higher concentrations of traffic-related air pollution, therefore, increasing the risk of these groups to related health effects, such as cervical dysplasia. In addition, Hispanic and black women are less likely to receive Pap screening services, have a higher incidence of cervical cancer, and have poorer survival after a cervical cancer diagnosis compared to white women in the U.S. [47-51]. The vulnerability of racial and ethnic minority groups to air pollution exposure in combination with lower adherence to screening is a pressing public health concern.

The results from this study have pertinent implications for health in the global context. Cervical cancer incidence and mortality is highest in the developing world, specifically in Africa and Central and South America [1,52]. This is largely due to the high prevalence of HPV infection in conjunction with limited access to screening services to detect precancerous lesions and early stage cervical cancer, as well as the lack of effective dissemination of the HPV vaccine and targeted vaccine delivery programs $[4,52,53]$. Moreover, due to increasing urbanization, specifically in Latin American cities, a larger portion of the population living in developing regions is being exposed to high levels of air pollution largely resulting from rapidly growing roadway and traffic density in urban areas $[54,55]$. The increased prevalence of exposure to traffic-related HAPs in these vulnerable populations may lead to an even higher incidence of cervical cancer.

\section{Conclusions}

This is the first study to evaluate the association between exposure to traffic-related HAPs and cervical dysplasia prevalence in a multi-ethnic sample of women. Our results suggest that women with high residential exposure to benzene, DPM, or PAHs have an increased prevalence of cervical dysplasia compared to women with relatively low exposure to these pollutants. Our findings highlight the need to continue to identify novel risk factors that contribute to cervical disease in conjunction with HPV infection. In addition, our findings may also be important in future cervical cancer prevention efforts as public health strategies are directed toward the detection, management, and prevention of cervical dysplasia.

\section{Additional file}

Additional file 1: Table S1. Associations between demographic variables and cervical dysplasia: Univariable analyses.

\section{Abbreviations}

aOR: Adjusted prevalence odds ratio; ASPEN: Assessment System for Population Exposure Nationwide; Cl: Confidence interval; CIN: Cervical intraepithelial neoplasia; DNA: Deoxyribonucleic acid; DPM: Diesel particulate matter; HAPs: Hazardous air pollutants; HPV: Human papillomavirus; $\mathrm{NO}_{x}$ : Nitrogen oxides; PAHs: Polycyclic aromatic hydrocarbons; SD: Standard deviation; U.S. EPA: United States Environmental Protection Agency.

\section{Competing interests}

The authors declare that they have no competing interests.

\section{Authors' contributions}

MES and PJL conceived and designed the study. PJL carried out the primary data analysis with the assistance of HED. MES and HED drafted the initial manuscript. MF was the PI of the parent study and provided input regarding study design and the assessment of cervical dysplasia. All authors contributed to revisions of the manuscript and read and approved the final manuscript.

\section{Acknowledgements}

This work was supported by the National Cancer Institute (R03 CA143965 awarded to MES and P01 CA082710 awarded to MF). 


\section{Author details}

'Department of Pediatrics, Section of Hematology-Oncology and Dan L. Duncan Cancer Center, Baylor College of Medicine, Houston, Texas. ${ }^{2}$ Department of Obstetrics and Gynecology, Paul L. Foster School of Medicine, Texas Tech University Health Sciences Center, El Paso, Texas.

Received: 4 February 2014 Accepted: 10 June 2014

Published: 13 June 2014

\section{References}

1. Jemal A, Bray F, Center MM, Ferlay J, Ward E, Forman D: Global cancer statistics. CA Cancer J Clin 2011, 61(2):69-90.

2. Gustafsson L, Ponten J, Zack M, Adami HO: International incidence rates of invasive cervical cancer after introduction of cytological screening. Cancer Causes Control 1997, 8(5):755-763.

3. Mathew A, George PS: Trends in incidence and mortality rates of squamous cell carcinoma and adenocarcinoma of cervix-worldwide. Asian Pac J Cancer Prev 2009, 10(4):645-650.

4. Parkin DM, Almonte M, Bruni L, Clifford G, Curado MP, Pineros M: Burden and trends of type-specific human papillomavirus infections and related diseases in the latin america and Caribbean region. Vaccine 2008, 26(Suppl 11):L1-L15.

5. Bosch FX, Lorincz A, Munoz N, Meijer CJ, Shah KV: The causal relation between human papillomavirus and cervical cancer. J Clin Pathol 2002, 55(4):244-265

6. Schiffman $\mathrm{MH}$, Castle P: Epidemiologic studies of a necessary causal risk factor: human papillomavirus infection and cervical neoplasia. J Natl Cancer Inst 2003, 95(6):E2.

7. Au WW: Life style, environmental and genetic susceptibility to cervical cancer. Toxicology 2004, 198(1-3):117-120

8. Plummer M, Herrero R, Franceschi S, Meijer CJ, Snijders P, Bosch FX de Sanjose S, Munoz N: Smoking and cervical cancer: pooled analysis of the IARC multi-centric case-control study. Cancer Causes Control 2003, 14(9):805-814

9. Moreno V, Bosch FX, Munoz N, Meijer CJ, Shah KV, Walboomers JM Herrero R, Franceschi S: Effect of oral contraceptives on risk of cervical cancer in women with human papillomavirus infection: the IARC multicentric case-control study. Lancet 2002, 359(9312):1085-1092.

10. Hildesheim A, Herrero R, Castle PE, Wacholder S, Bratti MC, Sherman ME, Lorincz AT, Burk RD, Morales J, Rodriguez AC, Helgesen K, Alfaro M, Hutchinson M, Balmaceda I, Greenberg M, Schiffman M: HPV co-factors related to the development of cervical cancer: results from a populationbased study in Costa Rica. Br J Cancer 2001, 84(9):1219-1226.

11. Thomas DB, Ray RM, Koetsawang A, Kiviat N, Kuypers J, Qin Q, Ashley RL, Koetsawang S: Human papillomaviruses and cervical cancer in Bangkok. I. Risk factors for invasive cervical carcinomas with human papillomavirus types 16 and 18 DNA. Am J Epidemiol 2001, 153(8):723-731.

12. Denny LA, Franceschi S, de Sanjose S, Heard I, Moscicki AB, Palefsky J: Human papillomavirus, human immunodeficiency virus and immunosuppression. Vaccine 2012, 30(Suppl 5):F168-F174

13. de Freitas AC, Gurgel AP, Chagas BS, Coimbra EC, do Amaral CM: Susceptibility to cervical cancer: an overview. Gynecol Oncol 2012, 126(2):304-311.

14. Technology transfer network: air toxics web site. [http://www.epa.gov/ ttnatw01/allabout.html]

15. IARC: IARC monographs on the evaluation of carcinogenic risks to humans. Volume 46. Diesel and gasoline engine exhausts and some nitroarenes. IARC Monogr Eval Carcinog Risks Hum 1989, 46:1-458.

16. IARC: IARC monographs on the evaluation of carcinogenic risks to humans. Volume 100F. Chemical agents and related occupations. IARC Monogr Eval Carcinog Risks Hum 2012, 100(Pt F):9-562.

17. IARC: IARC monographs on the evaluation of carcinogenic risks to humans. Volume 82 . Some traditional herbal medicines, some mycotoxins, naphthalene and styrene. IARC Monogr Eval Carcinog Risks Hum 2002, 82:1-556.

18. Pope CA 3rd, Burnett RT, Thun MJ, Calle EE, Krewski D, Ito K, Thurston GD: Lung cancer, cardiopulmonary mortality, and long-term exposure to fine particulate air pollution. JAMA 2002, 287(9):1132-1141.

19. Raaschou-Nielsen O, Bak H, Sorensen M, Jensen SS, Ketzel M, Hvidberg M, Schnohr P, Tjonneland A, Overvad K, Loft S: Air pollution from traffic and risk for lung cancer in three Danish cohorts. Cancer Epidemiol Biomarkers Prev 2010, 19(5):1284-1291.
20. Boeglin ML, Wessels $D$, Henshel D: An investigation of the relationship between air emissions of volatile organic compounds and the incidence of cancer in Indiana counties. Environ Res 2006, 100(2):242-254.

21. Raaschou-Nielsen O, Andersen ZJ, Hvidberg M, Jensen SS, Ketzel M, Sorensen M, Hansen J, Loft S, Overvad K, Tjonneland A: Air pollution from traffic and cancer incidence: a Danish cohort study. Environ Health 2011 10:67

22. Vinceti M, Rothman KJ, Crespi CM, Sterni A, Cherubini A, Guerra L, Maffeis G, Ferretti E, Fabbi S, Teggi S, Consonni D, De Girolamo G, Meggiato A, Palazzi G, Paolucci P, Malagoli C: Leukemia risk in children exposed to benzene and PM10 from vehicular traffic: a case-control study in an Italian population. Eur J Epidemiol 2012, 27(10):781-790.

23. Whitworth KW, Symanski E, Coker AL: Childhood lymphohematopoietic cancer incidence and hazardous air pollutants in southeast Texas, 1995-2004. Environ Health Perspect 2008, 116(11):1576-1580.

24. Visser $\mathrm{O}$, van Wijnen $\mathrm{JH}$, van Leeuwen FE: Residential traffic density and cancer incidence in Amsterdam, 1989-1997. Cancer Causes Control 2004 15(4):331-339

25. Boffetta P, Dosemeci M, Gridley G, Bath H, Moradi T, Silverman D: Occupational exposure to diesel engine emissions and risk of cancer in Swedish men and women. Cancer Causes Control 2001, 12(4):365-374

26. Pham B, Rhodes $H$, Milbourne A, Adler-Storthz K, Follen M, Scheurer ME: Epidemiologic differentiation of diagnostic and screening populations for the assessment of cervical dysplasia using optical technologies. Gend Med 2012, 9(1 Suppl):S36-S47.

27. The ASPEN Model. [http://www.epa.gov/ttn/atw/nata/aspen.html]

28. Lupo PJ, Symanski E, Waller DK, Chan W, Langlois PH, Canfield MA Mitchell LE: Maternal exposure to ambient levels of benzene and neural tube defects among offspring: Texas, 1999-2004. Environ Health Perspect 2011, 119(3):397-402.

29. Reynolds P, Von Behren J, Gunier RB, Goldberg DE, Hertz A, Smith DF: Childhood cancer incidence rates and hazardous air pollutants in California: an exploratory analysis. Environ Health Perspect 2003, 111(4):663-668.

30. Nye MD, Hoyo C, Huang Z, Vidal AC, Wang F, Overcash F, Smith JS, Vasquez B, Hernandez B, Swai B, Oneko O, Mlay P, Obure J, Gammon MD, Bartlett JA, Murphy SK: Associations between methylation of paternally expressed gene 3 (PEG3), cervical intraepithelial neoplasia and invasive cervical cancer. PLoS One 2013, 8(2):e56325.

31. Tomita LY, D'Almeida V, Villa LL, Franco EL, Cardoso MA: Polymorphisms in genes involved in folate metabolism modify the association of dietary and circulating folate and vitamin B-6 with cervical neoplasia. J Nutr 2013, 143(12):2007-2014

32. Grimm C, Watrowski R, Polterauer S, Baumühlner K, Natter C, Rahhal J, Heinze G, Schuster E, Hefler L, Reinthaller A: Vascular endothelial growth factor gene polymorphisms and risk of cervical intraepithelial neoplasia. Int J Gynecol Cancer 2011, 21(4):597-601.

33. Sexton $\mathrm{K}$, Linder $\mathrm{SH}$, Marko D, Bethel $\mathrm{H}$, Lupo PJ: Comparative assessment of air pollution-related health risks in Houston. Environ Health Perspect 2007, 115(10):1388-1393.

34. Appleby P, Beral V, de Gonzalez Berrington A, Colin D, Franceschi S, Goodill A, Green J, Peto J, Plummer M, Sweetland S: Carcinoma of the cervix and tobacco smoking: collaborative reanalysis of individual data on 13,541 women with carcinoma of the cervix and 23,017 women without carcinoma of the cervix from 23 epidemiological studies. Int J Cancer 2006, 118(6):1481-1495

35. Gadducci A, Barsotti C, Cosio S, Domenici L, Riccardo Genazzani A: Smoking habit, immune suppression, oral contraceptive use, and hormone replacement therapy use and cervical carcinogenesis: a review of the literature. Gynecol Endocrinol 2011, 27(8):597-604.

36. Roura E, Castellsague X, Pawlita M, Travier N, Waterboer T, Margall N, Bosch FX de Sanjose S, Dillner J, Gram IT, Tjonneland A, Munk C, Pala V, Palli D, Khaw KT, Barnabas RV, Overvad K, Clavel-Chapelon F, Boutron-Ruault MC, Fagherazzi G, Kaaks R, Lukanova A, Steffen A, Trichopoulou A, Trichopoulos D, Klinaki E, Tumino R, Sacerdote C, Panico S, Bueno-de-Mesquita HB: Smoking as a major risk factor for cervical cancer and pre-cancer: results from the EPIC cohort. Int J Cancer 2013

37. Trimble CL, Genkinger JM, Burke AE, Hoffman SC, Helzlsouer K, Diener-West M, Comstock GW, Alberg AJ: Active and passive cigarette smoking and the risk of cervical neoplasia. Obstet Gynecol 2005, 105(1):174-181. 
38. Pratt MM, Sirajuddin P, Poirier MC, Schiffman M, Glass AG, Scott DR, Rush BB, Olivero OA, Castle PE: Polycyclic aromatic hydrocarbon-DNA adducts in cervix of women infected with carcinogenic human papillomavirus types: an immunohistochemistry study. Mutat Res 2007, 624(1-2):114-123.

39. Melikian AA, Sun P, Prokopczyk B, El-Bayoumy K, Hoffmann D, Wang X, Waggoner $S$ : Identification of benzo[a]pyrene metabolites in cervical mucus and DNA adducts in cervical tissues in humans by gas chromatographymass spectrometry. Cancer Lett 1999, 146(2):127-134.

40. Pilger A, Rudiger HW: 8-Hydroxy-2'-deoxyguanosine as a marker of oxidative DNA damage related to occupational and environmental exposures. Int Arch Occup Environ Health 2006, 80(1):1-15.

41. Sorensen M, Autrup H, Moller P, Hertel O, Jensen SS, Vinzents P, Knudsen LE, Loft S: Linking exposure to environmental pollutants with biological effects. Mutat Res 2003, 544(2-3):255-271.

42. Wang F, Li C, Liu W, Jin Y: Effect of exposure to volatile organic compounds (VOCs) on airway inflammatory response in mice. J Toxicol Sci 2012, 37(4):739-748

43. Alam S, Conway MJ, Chen HS, Meyers C: The cigarette smoke carcinogen benzo[a]pyrene enhances human papillomavirus synthesis. J Virol 2008, 82(2):1053-1058

44. Gray SC, Edwards SE, Miranda ML: Race, socioeconomic status, and air pollution exposure in North Carolina. Environ Res 2013, 126:152-158.

45. Gwynn RC, Thurston GD: The burden of air pollution: impacts among racial minorities. Environ Health Perspect 2001, 109(Suppl 4):501-506.

46. Brochu PJ, Yanosky JD, Paciorek CJ, Schwartz J, Chen JT, Herrick RF, Suh HH: Particulate air pollution and socioeconomic position in rural and urban areas of the Northeastern United States. Am J Public Health 2011, 101(Suppl 1):S224-S230.

47. Bazargan M, Bazargan SH, Farooq M, Baker RS: Correlates of cervical cancer screening among underserved Hispanic and African-American women. Prev Med 2004, 39(3):465-473.

48. Howlader N, Noone AM, Krapcho M, Garshell J, Neyman N, Altekruse SF, Kosary CL, Yu M, Ruhl J, Tatalovich Z, Cho H, Mariotto A, Lewis DR, Chen HS, Feuer EJ, Cronin KA (Eds): SEER Cancer Statistics Review, 1975-2010. : National Cancer Institute. Bethesda, MD; http://seer.cancer.gov/csr/ 1975_2010/, based on November 2012 SEER data submission, posted to the SEER web site, April 2013.

49. del Carmen MG, Avila-Wallace M: Effect of health care disparities on screening. Clin Obstet Gynecol 2013, 56(1):65-75.

50. Howe HL, Wu X, Ries LA, Cokkinides V, Ahmed F, Jemal A, Miller B, Williams M, Ward E, Wingo PA, Ramirez A, Edwards BK: Annual report to the nation on the status of cancer, 1975-2003, featuring cancer among U.S. Hispanic/Latino populations. Cancer 2006, 107(8):1711-1742.

51. Niccolai LM, Julian PJ, Bilinski A, Mehta NR, Meek Jl, Zelterman D, Hadler JL, Sosa L: Geographic poverty and racial/ethnic disparities in cervical cancer precursor rates in Connecticut, 2008-2009. Am J Public Health 2013, 103(1):156-163.

52. Forman D, de Martel C, Lacey CJ, Soerjomataram I, Lortet-Tieulent J, Bruni L, Vignat J, Ferlay J, Bray F, Plummer M, Franceschi S: Global burden of human papillomavirus and related diseases. Vaccine 2012, 30(Suppl 5):F12-F23.

53. Sankaranarayanan R: HPV vaccination: the promise \& problems. Indian J Med Res 2009, 130(3):322-326.

54. Bell ML, Davis DL, Gouveia N, Borja-Aburto VH, Cifuentes LA: The avoidable health effects of air pollution in three Latin American cities: Santiago, Sao Paulo, and Mexico City. Environ Res 2006, 100(3):431-440.

55. Molina MJ, Molina LT: Megacities and atmospheric pollution. J Air Waste Manag Assoc 2004, 54(6):644-680.

doi:10.1186/1476-069X-13-52

Cite this article as: Scheurer et al:: Association of traffic-related hazardous air pollutants and cervical dysplasia in an urban multiethnic population: a cross-sectional study. Environmental Health 2014 13:52.

\section{Submit your next manuscript to BioMed Central and take full advantage of:}

- Convenient online submission

- Thorough peer review

- No space constraints or color figure charges

- Immediate publication on acceptance

- Inclusion in PubMed, CAS, Scopus and Google Scholar

- Research which is freely available for redistribution

Submit your manuscript at www.biomedcentral.com/submit
C Biomed Central 